\title{
O CORPO QUE APRENDE: O ESTUDO DOS TRAÇOS DE CARÁTER COMO FERRAMENTA DOCENTE NOS ANOS INICIAIS DO ENSINO FUNDAMENTAL
}

\author{
Laila Fernanda dos Santos - SEDUC /MT \\ lailafernandabobadilha@gmail.com
}

\begin{abstract}
RESUMO
A temática desta pesquisa surge como tentativa de alinhar os estudos da Psicologia Corporal, através dos postulados de Reich e Lowen e suas contribuições ao Ensino Fundamental durante o Ensino Emergencial Remoto (ERE). O Objetivo desta pesquisa é investigar como o estudo dos Traços de caráter e da Bioenergética podem contribuir para o processo de ensino-aprendizagem de uma turma de $3^{\circ}$ ano do Ensino Fundamental de uma escola da Rede Pública Estadual de Mato Grosso. A metodologia utilizada foi o estudo de caso de natureza exploratória de abordagem mista utilizando o método quantitativo e o qualitativo. O estudo revelou, através dos apontamentos da análise dos traços que, o professor compreenderá com maior facilidade os meios como os alunos interagem socialmente, facilitando a interação social e o engajamento dos discentes, ainda que remotamente.
\end{abstract}

Palavras-chave: Bioenergética; Traços de Caráter; Ensino Fundamental.

\section{INTRODUÇÃO}

Esta pesquisa abordará o estudo dos traços de caráter, através da Bioenergética e sua aplicabilidade no processo de ensino-aprendizagem em uma turma de $3^{\circ}$ do Ensino Fundamental de uma escola da rede estadual de ensino de Mato Grosso, durante o período 
de Ensino Remoto Emergencial. De acordo com Mota (2016) a Bioenergética propõe investigar o papel da energia no funcionamento de organismos vivos, onde as experiências emocionais dão origem a certos padrões musculares que bloqueiam o livre fluxo de energia no corpo.

A Bioenergética fundamenta-se no estudo dos Traços de Caráter, preconizados por Wilhelm Reich (1933) - o caráter refere-se ao modo de existir e comportar-se de um indivíduo, que tende a enrijecer-se e cronificar-se. Além da perspectiva psicológica, "o caráter tem, [...] uma profunda relação com os aspectos históricos e sociais" (CASTRO, 2016, p.01).

No âmbito escolar, nunca se demandou tanto que os profissionais da educação, principalmente dos primeiros anos escolares, apresentem a compreensão do desenvolvimento da criança, bem como da aprendizagem (CRISTOFOLINI, 2009). Neste pensamento, quanto mais cedo soubermos do modo como a mente do ser humano "funciona" e interage entre seus pares, maiores as chances de proporcionar experiências educacionais e sociais enriquecedoras.

Por conta da Pandemia de COVID19, o status quo da sociedade foi temporariamente modificado, por força da necessidade introduziu-se informatização do ensino através da instituição do Ensino Remoto Emergencial (ERE). A forma de interação entre professor e aluno passou a ser operacionalizada pelas Tecnologias de Informação e Comunicação (TIC). neste ato, gestos, expressões corporais e faciais são inseridos como linguagem no discurso de seus autores (professor-aluno, aluno-professor).

Considerando a temática e os sujeitos da pesquisa, partiu-se da seguinte questão norteadora: Como a Bioenergética, por meio do estudo dos traços de Caráter pode contribuir para o processo de ensino-aprendizagem remoto no $3^{\circ}$ ano do Ensino Fundamental da E.E. Manoel Cavalcanti Proença?

Desta reflexão central, levantou-se como objetivo principal: Investigar como o estudo dos Traços de caráter e da Bioenergética podem contribuir para o processo de ensinoaprendizagem do $3^{\circ}$ do Ensino Fundamental no Ensino Emergencial Remoto. Como objetivos específicos: Investigar como cada traço de caráter prioriza as relações sociais 


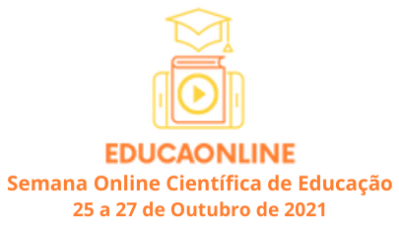

no ambiente escolar; investigar quais estratégias didáticos-metodológicas podem ser mais eficientes no ambiente remoto de acordo com cada traço de caráter.

\section{METODOLOGIA}

O presente estudo configurou-se num estudo de caso com abordagem mista que consiste em combinar a análise quantitativa com análise qualitativa de natureza exploratória. A abordagem mista, por sua vez, faz referência a um procedimento de coleta de dados, análise e combinação de técnicas tanto quantitativas como qualitativas em um mesmo desenho de pesquisa (CRESWELL; PLANO CLARK, 2011). As técnicas utilizadas para coletar dados foram por meio do levantamento bibliográfico, análise documental e roteiro de observação.

\section{RESULTADOS E DISCUSSÕES}

Localizada na região sul da cidade de Cuiabá, a Escola Estadual Manoel Cavalcanti Proença atende atualmente 644 alunos matriculados, distribuídos entre no Ensino Fundamental I e II. A turma do $3^{\circ}$ ano B, possui 24 alunos matriculados, sendo 14 alunos do sexo feminino e 10 do sexo masculino, de faixa etária entre 8 e 9 anos de idade.

As observações foram conduzidas pela professora com formação em pedagogia, que desenvolve os componentes curriculares de Língua Portuguesa, Matemática, História, Geografia, Ensino Religioso, Arte e Educação Física de forma unidocente, sendo orientada pela Coordenação de área da escola.

Através da análise do acervo digital da professora, correspondente às atividades desenvolvidas pelos alunos, pôde-se realizar a observação da expressão e da apresentação corporal de cada aluno, a partir disso, realizou-se a análise combinada das principais características e conflitos psicoemocionais de cada traço, esta ação baseou-se nos estudos de Análise Corporal de Reich e da Bioenergética de Lowen, a partir disso, foi possível elencar possíveis ações pedagógicas mais adequadas à cada traço. A ideia é que mediadas pela ação do professor, os alunos sejam estimulados conforme suas principais 
motivações. A tabela 1 apresenta de forma analítica, possíveis conflitos emocionais que cada traço apresenta, segundo os postulados de Reich e Lowen.

Tabela 1 - Formato Corporal dos traços, conflitos e possibilidades pedagógicas

\begin{tabular}{|c|c|c|c|}
\hline $\begin{array}{l}\text { FORMATO } \\
\text { CORPORAL } \\
\end{array}$ & $\begin{array}{l}\text { TRAÇO DE } \\
\text { CARÁTER }\end{array}$ & $\begin{array}{l}\text { CONFLITOS } \\
\text { INTERNOS }\end{array}$ & $\begin{array}{l}\text { POSSIBILIDADES } \\
\text { PEDAGÓGICAS }\end{array}$ \\
\hline & Esquizoide & $\begin{array}{c}\text { Dificuldade de interagir } \\
\text { com pessoas, timidez e } \\
\text { diálogo interno } \\
\text { excessivo. }\end{array}$ & $\begin{array}{l}\text { Incentivar a criatividade, } \\
\text { realizar atividades em áudio, } \\
\text { incentivar a interação e o } \\
\text { trabalho em equipe. }\end{array}$ \\
\hline & Oral & $\begin{array}{l}\text { Dificuldade de pensar e } \\
\text { agir quando sozinho, } \\
\text { medo de ser esquecido } \\
\text { e/ou abandonado }\end{array}$ & $\begin{array}{l}\text { Incentivar ao discurso, expor } \\
\text { suas produções, incentivar a } \\
\text { expressar as emoções } \\
\text { percebidas por ele. }\end{array}$ \\
\hline & Psicopático & $\begin{array}{c}\text { Desconfiança, } \\
\text { necessidade de troca e } \\
\text { barganha }\end{array}$ & $\begin{array}{l}\text { Incentivar a liderança, } \\
\text { apontar claramente possíveis } \\
\text { ganhos por seu desempenho. }\end{array}$ \\
\hline & Masoquista & $\begin{array}{l}\text { Insegurança, medo de } \\
\text { exposição, medo } \\
\text { excessivo de errar. }\end{array}$ & $\begin{array}{l}\text { Incentivar a práticas e treinos } \\
\text { para reduzir erros, incentivar } \\
\text { a expressar suas emoções } \\
\text { com interações professor- } \\
\text { aluno, realizar atividades sem } \\
\text { exposição pessoal }\end{array}$ \\
\hline & Rígido & $\begin{array}{c}\text { Egoísmo, } \\
\text { competitividade, } \\
\text { necessidade de } \\
\text { priorização. }\end{array}$ & $\begin{array}{l}\text { Incentivar a liderança, } \\
\text { incentivar a cooperação e } \\
\text { participação em equipe, } \\
\text { experienciar o aprendizado } \\
\text { de perdas e frustrações. }\end{array}$ \\
\hline
\end{tabular}

Fonte: Lowen (1982).; autores da pesquisa (2021).

Ante ao exposto, o caráter se posiciona como o eixo que norteia a discussão do diálogo interno do indivíduo, expressas pela musculatura corporal (OLIVEIRA JUNIOR, 2016). As categorias dos traços elencados na Tabela 1 podem ser articuladas aos processos envolvidos no ambiente escolar, afim de promover experiências educacionais enriquecedoras. A Coluna "Conflitos internos", enumera características específicas de maior predominância em cada traço. Tais características são pensamentos, sentimentos e emoções subjetivas indicadas por Lowen (1982). Paralelamente, na Coluna "Possibilidades Pedagógicas", traça-se uma análise combinada, com ações subjetivas que 


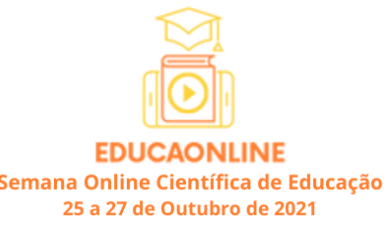

podem ser adotadas pelo professor, de acordo com o que se esperar de cada traço. No pensamento de Lowen, a subjetividade dos pensamentos ocorre paralelamente às emoções.

Dessarte a importância de se conhecer os postulados de Reich e Lowen podem operar como pano de fundo e orientar o trabalho do professor, que ao ler a expressão corporal de seus alunos, saberá suas necessidades, e a partir disso desenvolver seu trabalho de maneira mais eficiente.

\section{CONSIDERAÇÕES FINAIS}

Com este estudo foi possível concluir que a Análise Bioenergética tem o potencial de trazer inúmeras contribuições aos educadores e educandos, uma vez que seus apontamentos são capazes de subsidiar experiências sociais significativas de modo intrapessoal e interpessoal, contribuindo nos processos de ensino-aprendizagem. $\mathrm{Na}$ complexidade do Ensino Remoto Emergencial é necessário compreender a realidade vivida para ser possível a visualização de práticas pedagógicas coerentes à realidade. Para tanto, considerar o caráter na dinâmica educacional é uma alternativa para a superação dos desafios impostos no dia a dia escolar.

A busca pelas correlações entre caráter e aprendizagem, apesar de não ser determinante e nem categórica, pode orientar pesquisa e prática pedagógica, haja vista sua potencialidade para uma compreensão mais ampla dos processos de ensino-aprendizagem e possibilidades de intervenção das interações dos indivíduos em sociedade.

Todavia, considerando a proporção deste estudo, ante a seus resultados observou-se que muito pouco se sabe ainda da potencialidade que os entrelaçamentos da Psicologia Corporal, da Análise dos Caráteres e da Pedagogia podem produzir. Desvelando a necessidade de pesquisas investigativas mais aprofundadas na temática sobre a integração corpo e mente, sobretudo as relações entre o estudo das estruturas de caráter e suas aplicabilidades nos anos iniciais do Ensino Fundamental.

\section{REFERÊNCIAS}


CASTRO, Gisele Fontenelle de Oliveira. Caráter e couraça: estruturas sólidas na sociedade líquido-moderna? In: VOLPI, José Henrique; VOLPI, Sandra Mara (Org.) XXI CONGRESSO BRASILEIRO DE PSICOTERAPIAS CORPORAIS. Anais. Curitiba: Centro Reichiano, 2016, pp. 260-274. [ISBN - 978-85-69218-01-2]. Disponível em: www.centroreichiano.com.br/artigos_anais_congressos.htm. Acesso em 01.ago.2021.

CRESWELL, J. W.; PLANO CLARK, V. L. Designing and conducting mixed methods research. 2nd. Los Angeles: SAGE Publications, 2011.

CRISTOFOLINI, Gloria Maria Alves Ferreira. A psicologia corporal na sala de aula. In: VOLPI, José Henrique; VOLPI, Sandra Mara (Org.). Anais. 14 ${ }^{\circ}$ CONGRESSO BRASILEIRO DE PSICOTERAPIAS CORPORAIS. Curitiba/PR. Centro Reichiano, 2009. CD-ROM. [ISBN - 978-85-87691-16-3]. Acesso em01.ago.2021.

LOWEN, Alexander. Bioenergética. São Paulo: Summus, 1982.

MOTA, Maria V. A visibilidade humana através do corpo numa perspectiva reichiana: o corpo da criança na pedagogia. In: VOLPI, José Henrique; VOLPI, Sandra Mara (Org.) XXI CONGRESSO BRASILEIRO DE PSICOTERAPIAS CORPORAIS. Anais. Curitiba: Centro Reichiano, 2016, pp. 25-36. [ISBN - 978-85- 69218-01-2]. Disponível em: www.centroreichiano.com.br/artigos_anais_congressos.htm. Acesso em 15.ago.2021.

OLIVEIRA JÚNIOR. Wellington Roriz de. Integração corpo/mente na Análise Bioenergética de Alexander Lowen: [manuscrito]: a relação entre o adoecimento corporal e as estruturas de caráter. Dissertação Pós-graduação. Goiânica: UFG. 2016.

REICH, Wilhelm. Análise do Caráter. São Paulo: Martins Fontes, 1995.

REICH, Wilhelm; SCHMIDT, V. Psiconálisis y Educación 1. (Ramón Garcia, Nuria Pérez de Lara y Sebastián Alemany. Trad). 2. ed. Barcelona: Editorial ANAGRAMA, 1980. 